\title{
Social Media and Social Relationship among Youth: A Changing Pattern
} and Impacts in Bangladesh

\author{
Md. Al Hasibuzzaman ${ }^{1}$, Aurthy Noboneeta ${ }^{2}$, Mina Begum $^{3}$, and Nowshin Nawal Chowdhury Hridi ${ }^{4}$ \\ ${ }^{1}$ Institute of Nutrition and Food Science, University of Dhaka, Bangladesh; ${ }^{2}$ Dept. of Mass Communication and Journalism, \\ University of Dhaka, Dhaka, Bangladesh; ${ }^{3}$ Dept. of Islamic Studies, University of Dhaka, Dhaka, Bangladesh; ${ }^{4}$ Dept. of \\ Dance, University of Dhaka, Dhaka, Bangladesh. \\ *Correspondence: hasibuzzaman.hsb@gmail.com (Md. Al Hasibuzzaman, Institute of Nutrition and Food Science, University \\ of Dhaka, Bangladesh).
}

\begin{abstract}
Social media is a platform for people to share their varied points of view on life, as well as their experiences, facts, videos, and other information. Digitalization brings the world into more connectivity, increases social diversity and variety, and leads to a significant change in the structure, systems, traditions, and norms. In the twenty-first century, communication is the most important part of social and professional communication. In the last 15 years, social media has changed the way, how we communicate. Faster communication and cheaper ways have become the most valuable things in the modern world. In the past 5 years, Bangladesh has also been influenced by western culture and has seen a rapid growth in social media use. Social media platforms have become deeply integrated into many day-to-day interactions in an increasingly digital society. The vast majorities of Bangladeshis own a Smartphone and use social media on a regular basis. Because of the digital attachment, how the users' emotional well-being as well as offline interpersonal relationships have been impacted by their use of relationships. Social media is the platform for people to share their varied points of view on life, as well as their experiences, facts, videos, and other information. This article explored social relationships in the face of growing dependency on social media or virtual communication. It has also been figured out that the risk factor is mainly related to social media use and spread mainly among youth in Bangladesh. The findings suggest the presence of cyber bullying, hate speech, and blasphemy have been polarizing the relationship in parochial senses - communal, ethnic, lingual, and others. Based on secondary sources, the article indicates the necessity of dealing with several issues like socialization and mental health issues on a national level and how they affect our lives.
\end{abstract}

Keywords: Social media, Social relationships, Changing social life, and Health impacts.

\section{INTRODUCTION:}

The beginning of the twenty-first century Internet boom made it more accessible and communicable to people. People can access data more quickly and it can be easily accessible anywhere. Social media is one of the best ways to share photos, videos, thoughts, microtweets, etc. Modern social media attracts people from all ages. But the younger generations are mostly passionate about using it.

The increased use of social media has influenced a new culture of interpersonal communication and collaboration among young people. It helped bring friends and family closer to those who lived in distant locations. It has a very low additional cost for connectivity 
needs, sharing information anywhere in the world, texting opinions and updating each other on events in their lives. Recent studies have also shown that social media facilitates business promotion and interpersonal communication smoothly and also provides a platform for individuals to express themselves (Amedie, 2015) But there are many problems that also happen because of using social media.

These problems include lack of emotional connection, poor face-to-face communication skills, communicating inauthentic expressions of feelings, and making face-to-face interactions disconnected. Bangladesh's government cannot control cyber bullying, hate speech, and many more. Mental health is a big issue. This article will review social media problems and social relationship issues.

\section{Problem Statement}

Before using social media, there was more emotional bonding in all relationships, and that made the relationships mostly strong. But after she came into our lives, our lives started to become online social media based. So, our lives are starting to become virtual. As time passes, our lives become more and more dependent on online social media. Because of the lack of face-to-face communication, connections are not as solid as they were before the use of social media (Baskaran et al., 2017). This is because people may communicate their thoughts as well as their feelings on social media, which somehow results in no strong bonds forming. We might refer to social media friends as "fake friends" because they are unable to feel what you feel about anything or recognize your importance.

\section{Social relationship}

People are not outside the reach of society. Humans are social creatures. As a result, we must review several aspects of our society. It is impossible to live alone. As a result, people form a lot of relationships in our society. These social interactions are reflected in our social system. People go through several stages of social interaction from childhood to death, yet one can't survive without them. It is in our instinct to make social connections. Roy Baumeister, a psychologist, has established a theory that focuses on our basic needs in order to meet these wants. According to the notion, "each of us is born with a need to seek out, develop, maintain, and defend strong social ties."
People seek relationships with people at work, school, in our communities and religious groups, on sports teams, in online communities, and in other social settings to meet this need. These interactions, according to Baumeister, these relationships will help us feel that we are never alone, as we all belong to a social community.' Even being away or being deprived of people can be physically as well as mentally devastating. If we think of our friends, we can easily understand how much this relationship is important and how the relationship actually works in our lives and affects us both physically and psychologically (Bekalu et al., 2019).

"According to research, online relationships can be as emotionally close and fulfilling as face-to-face relationships. If we had social relationships, we would feel connected to others in ways that we can't experience if we are alone or when we have only superficial relationships" (Butler and Matook, 2015). Living in a society People must undergo different dimensions. Our social structure indicates our social relationships. From childhood to our death, we face different phases of our social relationships, but we can't live without them. A social relationship is one that develops between people who share a common understanding of something. According to Springer, "Social ties relate to the links that exist between people who have repeated contacts that are regarded to have personal importance by the participants." Ties that are ephemeral include those between family members, neighbors, friends, coworkers, and other related associates, but do not include social relationships. In general, encounters and interactions are incidental or regarded as being of minor importance. According to the sage research method, "the term "social relationships" is used to describe relationships between two or more people that are primarily based on their view of social attributes.

Personal or interpersonal interactions, on the other hand, are terminology used to characterize relationships that are largely based on interlocutors' psychological features, such as personality or internal motivation. So, in a word, "social relationship" indicates all types of inter-personal interaction that can occur in a family, institution, or any kind of organization. 


\section{Forms/feature}

Social relationships are formed primarily on the basis of some fundamental concepts such as various types of social organization, social structure, various social movements, and social systems. But the most fundamental feature of social relationships is social interaction. We meet so many people in our society, like school, college, religious occasions or any kind of movement, but when we get to interact with them and share our knowledge, and then our relationship starts to build. Without interaction, a relationship cannot be for-med. A relationship is established between people as soon as they share knowledge with one another. A particular relationship between people consequently influences the way knowledge is shared (Giddens, 1984). Social relationships build up with proper interaction. Interaction can happen in cooperation, competition, social conflict, accommodation, and so on. Relationships are important for everyone. Here I will mention two theories that are very much related to interactions. Those are social exchange theory and rational choice theory. The theory named "social exchange theory," which promotes the idea that relationships are essential for our daily life, is named. Social exchange theory demonstrates that forming relationships is really beneficial because of exchange. Each party in the relationship has some particular beliefs and perspectives that get an opportunity to be exchanged within the interaction, and it works so positively. There is another theory named the Rational Choice Theory. This theory explains how individuals make decisions. Individuals here make decisions based on their own self-interest, which will benefit them greatly

\section{Background information}

Before using social media, in our society, relationships were face-to-face interaction based. We also have so many platforms to build and strengthen our bonds with each other, like in educational institutions, different social organizations, any social or religious events or festivals, or in movements where we come and interact with a lot of people and thus form our relationships. Besides that, we all regularly go to our relatives' houses and have a wonderful time with them. As I have mentioned before, interaction is the fundamental feature of social relationships. Scholars also build up so many theories and put emphasis on social inter- action to build relationships. According to relationship model theory of Fiske, (Fiske, 1992) people are sociable fundamentally. They naturally shape their social life on the basis of their relationships with others. In this theory, Fiske proposed four elementary mental models: communal sharing, authority ranking, equality matching, and market pricing. He believed all thinking about social relationships is based on these four models. Communal sharing relationships are based on the conception of some group of people as being undifferentiated and equivalent. In this type of relationship, people think to themselves that they all have some common sharing substance, like close kinship. Here, communalities are the main focus. Authority ranking relationships are formed on the basis of people who are ordered along some hierarchical dimensions of society. This relationship is authority-based. Relationships between people from different backgrounds, such as those in the military, are an example. The equality matching relationship model focuses on equal or balanced relationships. In this model, people prefer those who feel equal. Here, people value equality (Christensen, 2018). The market pricing relationship model is proportionality-based in relationships. Here, how a person stands in proportion to others is mainly noticed. The people who organized themselves into cost-benefit ratios and other calculations are governed by this model.

\section{Social system: Ancient Stages- Present ages}

We are living in a social world. We have reached the present society through many steps. Societies have changed over the past 12,000 years. Sociologists have explained these changes in their own way. They use different terms and criteria to define the development of human society. Karl Marx's story of society is all about social conflict, which is related to the economic system. One of the sociologists, Max Weber, tells a different tale about human development. He shows that the power of ideas shapes society. But Gerherd Lensky used the term "socio cultural revolution" to define human history. That means the changes occurred in a society gaining new technology. Society is a community, nation, or broad grouping of people having common traditions, institutions, and collective activities and interests (Webster, 2012). For survival as a human in human society, relationships among 
people have always been a necessity. We can say relationships are the foundation on which humans decide to reproduce and, ultimately, a society is formed by them. There is a huge difference in relationships between people in the past and present society. Gerhard Lensky, one of the leading sociologists of today's world, describes how society has changed over the past years. He actually pointed to technology as shaping any society. He differentiated society based on technology, communication, and the economy. We mainly discuss Len Ski's view on the development of human society, the social system, and relationships among people. By discussing his works, we can easily understand the differences among societies that existed throughout human history. He divided the whole society into five types: 1 ). hunting and gathering society, 2). horticultural and pastoral society, 3). agrarian, 4). industrial, and 5). post-industrial.

\section{Hunting and Gathering Society}

From the time of 3 million years ago, our species appeared. Until about 12000 years ago, humans were nomadic foragers, also known as hunters and gatherers. In the simplest of all societies, they were prehistoric nomadic groups that relied on nature, utilized fire and exquisite technology to hunt and gather food and materials to meet their basic needs. They have little ability to control their environment, so they work together, and the formation of families is seen in this society. The number of people in this society was just a few dozens. They spent most of the time hunting wild animals and gathering plants. In this society, men typically hunted large game while women collected vegetation. People collected enough food to satisfy all, but not excessively. That's why in this society, division of labor was nonexistent (Giddens, 1984). Hunting and gathering society depends on the family to do things like hunting and gathering. They were all leading much the same life. Most of the time, they are looking forward to collecting their next meal. It is said that hunting and gathering society's people come close to being socially equal. In short, we can say this society was family-centered and had little social inequality.

\section{Horticultural and Pastoral Society}

About 10,000 to 12,000 years ago, people invented a new type of technology that began to change the lives of human beings. By using these tools, they dig the soil to plant seeds. These inventions allowed people to give up hunting and gathering. But not all societies did this. People living in dry regions were more likely to adopt pastoralism (Greenhow, 2011). That's why this society is called the "horticultural and pastoral society." The number of people was increasing, so hunting and gathering societies for growing plants and raising animals increased food production. Social diversification and inequality in terms of gender and wealth were found in this society. This society's people were both nomadic and small-scale permanent and familycentered, similar to a hunting and gathering society. Religious thought was developing in this society.

\section{Agrarian Society}

Among all the scientific revolutionary inventions, wheels are one of them through which new civilizations were formed all over the world. About 5000 years ago, people invented a new technology with a wheel named "plow." With the help of plows, agricultural society developed in a place in the Middle East. Unlike other societies, this new breakthrough technology enabled large-scale crop cultivation. Food surplus increased the number of people and also made society unequal. Agrarian society allowed people to stay in one place. Women provided most of the food for other societies, but in agrarian society, men were positioned for dominance because they did hard work by using heavy metal plows pulled by large animals. Religion reinforces the power of the elite. Emerging as a distinct religious, political, and economic system, the family loses its significance and nuclear families are formed in this society.

\section{Industrial Society}

In the 18th century, people invented large machines with the help of water power and electricity instead of manmade technology, which led to the emergence of industrial plants. By inventing this large machinery, industrial society developed, but not in the whole world. It happened only in today's rich world, which led the whole world. That's why social inequality is more strongly founded in this society than in other societies. In industrial society, the whole world was changing rapidly (Lubis et al., 2017). Industrialization brought about technological advances such as the automobile, by which people can move quickly almost anywhere. People also changed their work from farms 
to factories. The result was that people's tendency to move from rural to urban, making social life more anonymous and increasing cultural diversity. As a result, family size and relationships between each other lose their significance gradually.

\section{Different Uses of Social Media for Maintaining Social Relationships}

The latest social media statistics show that 3.78 billion people use the media worldwide. Bangladesh is not an exceptional one. In fact, from 2020 to 2021, the number of internet users and social media users increased at a high rate and is still increasing. There were 47.61 million internet users in Bangladesh in January 2021, which increased by 7.7 million (+19\%) between 2020 and 2021 (Orben and Dunbar, 2017). According to The Digital Report, a report published in February by We Are Social, the total number of social media users in the country is 45 million. The most popular social media platforms are Facebook, WhatsApp, Messenger, YouTube, Vibes, Skype, Google+, Zoom, Instagram, Telegram, Bip, Snapchat, LinkedIn, Tiktok, etc. Now let me discuss how these platforms are used to maintain social media.

\section{Facebook}

The most popular social media platform, not only in Bangladesh but also worldwide, is Facebook. This platform was launched in 2004, and now its monthly users are 2.7 billion! The reason for the popularity of Facebook is its amazing features. Firstly, Facebook allows you to have social relationships without any geographical barrier. As there are no geographical restrictions, people can easily get connected with others worldwide. This unique feature is the main reason behind its huge acceptance. Despite this, Facebook allows its users to brand their company. It has now become a tool for learning, making income, showing talents, ecommerce, self-branding, gaming, financial services, technology, media, education, and business sectors, and so on. Gradually, Facebook is developing new features like Facebook Messenger, Instagram, Facebook groups, Facebook rooms, and much development is shown in the Facebook privacy sector. One can easily sign in to other internet sites by using their Facebook ID. Facebook groups are created to pursue a certain goal by a group of people. During the video situation in Bangladesh, the rate of social media en- gagement, especially Facebook engagement, has increased at a high rate. Now, people spend more time than before on messenger and chatting with others. They are also trying to achieve their self-employment goal through Facebook. During the lockdown, Facebook has become the primary source of information and has played an important role in maintaining social relationships. They use messenger or Facebook groups to communicate with others, and for business, education, branding, in all sectors, people have become highly dependent on Facebook these days. $79.13 \%$ of people in Bangladesh use Facebook. Using Facebook, users can keep in touch with old friends and those at other schools, as well as make new friends, join different groups according to their interests, promote their parties, and find out how many personal messages they received from their friends, as well as what other posts they made. Facebook constantly adds new features and people's pictures. Facebook's mission is to connect the world by sharing the power of sharing with people and making the world a more open and connected place (Parvez et al., 2019; Phoon, 2017).

Facebook is becoming more than a social networking site for entertainment, as it is also helping communities in a variety of ways, (2010) (Facebook as a tool for promoting global relation-ships). As a social network, Facebook is a place for people to exchange ideas by commenting on various issues.

\section{Messenger}

It's an app developed by Facebook. It is also very popular not only in Bangladesh, but also all over the world. This app is available in 111 languages and was initially released in 2011. Here, one can create groups for gossiping or for other needs. People can do group calls, send messages, do marketing, business, branding, advertisements, and so on. During lockdown, people become more dependent on messengers like Facebook. There is also a feature called "message lite," which uses less internet than the messenger app. around $23 \%$ of the population use messenger apps. It allows users to conduct video chats with whomever they choose. During a lockdown, people cannot meet with their close ones. So, they keep in touch with their close ones by phone, text, or video chat. Statistics show that more than 20 billion messages are exchanged between businesses and users each month on 
Facebook Messenger. By this year, messenger users are expected to grow to 2.4 billion.

\section{Twitter}

It was launched in 2006, and its monthly active users are 353 million. If your business is related to entertainment, sports, politics, technology, or marketing, you stand to earn tremendous engagement on Twitter. In Bangladesh, till June 2021, 1.26\% of people were active on this platform. Twitter is an emerging social media site that serves as a microblogging service that allows users to send and read text-based messages, which are called "tweets" (Lutgendorf et al., 2009). It is commonly used by people to keep in touch with friends, musicians, and celebrities on this site so that they can feel connected and learn to accept others' actions and feelings. Many people are fascinated with the individual lives of others on Twitter and are interested in knowing what is happening in each other's lives. In this specific example of social media, ties of distance have been shortened to people knowing exactly what one another is doing without physically interacting.

\section{WhatsApp}

Whatsapp lets contacts on mobile devices communicate with one another. More importantly, it allows parties to share information with those they prefer. WhatsApp is another popular social media platform to share ideas, media, and so on. It was launched in 2009 and its monthly users are 2 billion. It is mainly a popular social messaging app. This app is not the obvious choice for business-related activities, but it has a $98 \%$ open rate compared to $20 \%$ for email. If one uses WhatsApp for customer service and retention, one will quickly learn that the potential for brands on this underutilized channel is enormous. In Bangladesh, this app is mainly used for sending personal messages, media, or calling others. Though it is not as popular in Bangladesh as Facebook. It also has a unique feature called the "WhatsApp Business App," which is mainly used for connecting customers. WhatsApp web is also a good feature that enables you to connect to a PC or laptop. In Bangladesh, 22\% of users use WhatsApp. Here in this country, it is actively used as a primary communication platform.

\section{Instagram}

This social media platform was first released in 2010 . Its monthly users are 1.16 billion. Instagram is a UniversePG I www.universepg.com popular product-based enterprise, where influencers and instructors can thrive on this social network. Statistics show that Instagram is currently the sixth most used social media platform in the world. In 2021, the statistics show that $0.43 \%$ of people are active Instagram users in Bangladesh (Phoon, 2017).

\section{LinkedIn}

This social platform was first launched in 2003, and its monthly active users are 310 million. If one is looking for decision-makers who have the power to hire his company, stock his product, or partner with him, LinkedIn is the place to be. In Bangladesh, $1.22 \%$ is active users of LinkedIn. People use this to create a community that is business-related. This user rate is increasing day by day.

\section{Telegram}

It was first launched in 2013 and its monthly active users were 500 million till January 2021. Telegram is now the world's most downloaded app from the Google Play store. Telegram is cloud-based instant messaging software. It also provides the customer with an encrypted video calling system, file sharing, VoIP, and so many beautiful features. But the most important thing to mention is that it keeps users' data confidential. During lockdown, Bangladeshi people also use it more actively than before for its features.

\section{Google+}

Google+ is the official application for Google's popular social network on Android devices. It allows you to do everything that a desktop computer allows you to do. Users can easily upload photos and videos to their Google account directly from their terminal. Users can join video chats with up to eight other individuals using the "hangout" feature, as long as their Internet connection allows it. This network was first launched in 2011. 300 million monthly active users participate in this network and interact. During lockdown, the rate of using the function has become high worldwide, and Bangladesh is no exception to this.

\section{Zoom}

Zoom is a cloud-based online video communication social platform that allows one to set up virtual video as well as audio conferencing, webinars, live chat, and screen sharing. This platform enables you to interact, discuss, and express your thoughts so that you may 
accomplish more as a group. This app was first released in 2013, but it only became well known during the coronavirus pandemic of 2020. It was only this platform that was used frequently to stay in touch during the lockdown. The Zoom daily meeting participants in December 2020 were 350 million (Sawyer and Chen, 2012) At the height of the pandemic, over 90,000 schools used Zoom. Zoom was downloaded 485 million times in 2020. In 2020, over 45 billion minutes of webinars will be hosted on the platform. Bangladesh is also not beyond the zoom era. In our country, Zoom is also the most popular social media platform, especially when educational institutions start conducting online classes. Besides this, it is also being used in the business sector.

\section{Viber}

It was first launched in 2012, and its active users are 823 million per month. It is also a very popular platform for communicating with others. During COVID 19 , Viber saw a 17 percent increase in activations, a $21 \%$ increase in group messaging, and a $25 \%$ increase in one-to-one messaging in Bangladesh during the first half of 2020.The number of group messages exchanged grew by 48 percent, while community views increased by 77 percent. Viber also added a feature to use the Bangla font following the use of bangalees.

\section{Skype}

Skype is software that enables the world to have conversations. Due to its versatility and convenience, Skype has become increasingly popular. Millions of individuals and businesses use Skype to make video calls, voice calls, or group calls, send messages instantly, and share files with other people on Skype. One can use Skype on their mobile computer or tablet. Skype is a voice-over-IP service and software application developed by Niklas Zennstrom in 2003. It is internet-based telecommunication software that allows users to video chat, make voice conversations, and send text messages from their PCs, mobile phones, and tablets. It also aids pupils in getting through the class. In this manner, they become more committed to their goals and objectives. Bangladesh has a low level of acceptance for it.

\section{BiP}

The app's description claims, "BiP is a secure, easy-touse, free communication and life platform that delivers UniversePG I www.universepg.com seamless communication and a wide range of utility features like quick translations to 106 languages and currency rates." It was first released in 2013, and it now has 53 million users all around the world. According to Mobile Action research, BiP presently retains the \#1 spot in Bangladesh among the top messaging apps for the Android operating system. Data showed on Saturday that BiP has been downloaded by more than 50 million users worldwide, according to Google's app store.

\section{Pull factors}

According to safeopedia, "pull factor" is a geo-graphical term that is used to describe factors that attract people to a country, region, religion, organization, etc. In fact, the pull factor is a positive term that is used to explain what makes a place or anything attractive to those migrating from different lands. In other words, pull factors are those which attract or charm others and pull them to accept a change in their lives. The world is still in the midst of a global disease outbreak caused by a coronavirus, SARS-CoV-2, also known as COVID-19. To combat the COVID-19 epidemic, governments and public health organizations all over the world have implemented social distancing and stay-athome policies (World Health Organization, 2020). While particular limits vary by country, government strategies to deal with the coronavirus outbreak frequently include the closure of schools, non-essential physical stores and enterprises, as well as the restriction of public transit and places, as well as social gatherings. Public contact has plummeted as a result of these situations. In their efforts to stay socially connected, new problems develop for people all over the world. Industry estimates revealed that digital media usage skyrocketed during the initial months of the epidemic, as individuals spent more time at home owing to coronavirus lockdowns (Kemp, 2020). Such increases were especially prevalent for social media and messaging apps, but particularly remarkable was the unprecedented uptake of video conferencing apps and programs. Given people's widespread reliance on information and communication technologies (ICTs) for social interaction under such stay-at-home circumstances, this bears further examination. Digital communication technology has fully changed the social interaction process. People are now spending even 
more time with technology while consuming news media, watching television, using social media to connect with others, utilizing lifestyle apps to shop for groceries and other consumer goods, and engaging in home workouts (Nielsen Global Media, 2020).

Moreover, increased engagement with technology is required of students for educational purposes and for those now working from home. Online platforms are, by design, addictive (Alter, 2017). They encourage and pull people to endless scrolling and do not have a clear 'stop point', which is why it is so common for people to spend many hours online or engaged with social media. The same phenomenon exists with online or YouTube news videos. Now I will discuss some pull factors of using technology that determine social interaction.

1) Facebook: Facebook will be used by 46 million people in Bangladesh until July 2021. People are so attracted to using Facebook because of its amazing features that benefit users the most. Such as in business marketing, education, comedy, to get news updates, people are mostly dependent on Facebook.

2) Mobile phone: In the world, there is no person who does not use a mobile phone. During the pandemic, to maintain social connection with others, people spend more time on their mobile phones, as they don't need to go to a particular place to meet a particular person.

3) Youtube: Around $6.12 \%$ of people use Youtube in Bangladesh. A study by Pew Research found that Youtube is used $51 \%$ for educational purposes. It can be said that YouTube is very popular as a study medium. Besides this, people watch different types of content, such as commentary, memes, reviews, songs, videos, etc.

4) Whatsapp: Whatsapp's popularity stems from its security features. Here, users can keep their conversations secret, while users can call, send messages, or even mute conversations, and can easily communicate. Here, users can have control of their secret issues.

5) Messenger: Messenger is a very well-known messaging app. There is no one in the world that hasn't used Messenger. During COVID-19, Messenger became one of the most important apps to keep in touch with others. According to Nepoleonchat statistics, there will be 40,210,000 messenger users in Bangladesh as of February 20, 2021.

6) Telegram: It can migrating phone numbers or add a second number, users can upload multiple profile pictures, users can keep the chat secret, and users can also customize the look of telegrams, etc.

7) Instagram: There are 3500400 users in Bangladesh who are active on Instagram. People aged 18 to 24 are the largest group of people to use Instagram. It's a great platform to share videos, photos, and for messaging and calls.

8) Twitter: $2.96 \%$ of Bangladeshis use Twitter in August 2021, according to Star counter. It is mainly used for marketing purposes.

\section{Push Factor}

During lockdown, we encountered a variety of new and unusual scenarios. Many circumstances arose that we were completely unfamiliar with previously. For example, since human beings cannot survive without connecting with others, eliminating social distance appears completely unattainable. However, we had gone through a difficult period as a result of COVID 19. As a result, people have become increasingly reliant on online social media platforms to pass the time and communicate with others. In the education industry, an offline system is widely accepted-something no one could have predicted previously. It all occurs, though. As a result, the circumstances produced by the COVID-19 epidemic, I believe, is the driving force here. People embrace these social platforms as partners since they must stay at home for their own protection. Every student's life revolves around social media. Accessing information, providing information, and communicating via social media is often easier and more convenient. Students and tutors can communicate and learn from one another via these platforms.

1) Maintaining good relationships is crucial during a pandemic for several reasons, such as communicating with distant relatives who cannot be reached face-to-face, interacting with coworkers, friends, and colleagues, and trying to track down jobs.

2) There are new ways of entertaining yourself by playing games, listening to music, reading jokes and fun stories. 
1) Informing the public about current events, expressing opinions, making contributions and more social media related news people trust.

2) It takes a lot of effort to raise public awareness about any serious issue. People can easily go with any issue that is sensitive to the government and the people.

3) People can be manipulated so quickly to spread false news.

4) It takes a lot of time to get involved with social media. As a business, you should designate someone to consistently update your pages and profile with relevant content. Unwanted content is more and more common on social media.

5) Since anyone can make a phony record and do anything without being tailed, it has ended up being extremely straightforward for anyone to spook on the internet. Dangers, terrorizing messages, and bits of gossip can be sent to the majority to cause inconvenience and uproar in the general public.

6) Personal information and security can be hacked into the hands of cybercriminals if someone's account has been hacked in the past.

7) The addicting aspect of internet networking is terrible, and it may also exasperate people's lives. It can also waste people's time when they might be doing something else. Tasks and exercises that are lucrative are employed.

8) There are several examples of people who have used internet networking to conduct fraud and fraud.

After the emergence of the COVID-19 pandemic, we all had to go through new and also tough situations. But here, people accept social media platforms as their near companions to survive this problematic situation. Because spending time on social media is quite easy and convenient. It does not require a timetable, and even in any situation, social media can be used. So, these social media platforms catch all the attention of the world's people. Not only has this social media platform become an addiction for users. Social media isn't just for sharing photos and thoughts. Instagram and Facebook pages are very popular in Southeast Asia for local businesses online. Nowadays, Instagram is the most popular platform to promote a business. Facebook groups are very popular among Bangladeshi, Indian and Pakistani students. There are many groups that are famous for higher studies, research, photography, travel, and many more. Even when students are doing homework, they work as a group. Instant messenger is very helpful in this case. What's App is famous for video and audio calls. In South East Asia, many workers are sent abroad for work. From an Asian perspective, it is very common to use what's app and IMO as instant messaging. During the COVID-19 pandemic, instant messaging apps helped all over the world to take part in social relationships. Pandemic also shows that Zoom, Google Meet, Microsoft teams, and Skype are the best ways to work from home. Home offices were very popular during the pandemic, and it will continue into the next generation to work from home. During the COVID-19 pandemic almost 2 years ago, people used Facebook for entertainment purposes. Because of the heavy quarantine and long days, people are forced to stay at home and communicate primarily through social media. People not only communicate virtually, but they also use ecommerce websites to make purchases most of the time. time, ecommerce and online businesses have shown more than $230 \%$ growth in Southeast Asia (Sawyer and Chen, 2012). But with the increasing use of social media, people are staying away from close ones who are their real friends. But COVED 19 helps us to understand how much it is important to communicate physically with others, as people now become more dependent on social media and become isolated. Education and administrative work have also become dependent on virtual platforms. But virtual platforms can never provide them with the proper education that can be provided in offline classrooms.

\section{Mental health}

In today's world, mental illness is a severe and prevalent health problem. Every year, tens of millions of individuals are affected by it. Only a small percentage of people with depression obtains adequate treatment. This is the position paper examines several recent attempts to investigate the possibility of using social media postings as a new sort of marketing. People with mental illness might be seen through a new lens when it comes to comprehending and communicating with populations. Information obtained from social media has the potential to enhance standard survey methodologies by providing finer-grained 
measurements of behavior throughout time (Valenzuela et al., 2014). While dramatically increasing the size of the population sample. We finish by emphasizing how this line of research could aid in the development of instruments for detecting the onset of depressive illnesses. Individually, for healthcare agencies to use or on behalf of people, allowing those suffering from mental illness to be more independent and more conscious of their mental health. Adolescents can manage their mental health using social media, which is a relatively new medium. Indeed, many young people report using social media sites like Facebook and Twitter to escape the external pressures that are compromising their mental health. According to recent research, 57 percent of US teenagers have started relationships online, with 50 percent of those polled having "friended" someone on Facebook (or equivalent) to express their love interest. Clearly, social media has its own way of playing an increasingly important role in adolescent social, mental, and emotional development. Social media may provide new types of communication and social connection, but there were concerns about how much time young people spent online at first. According to the study, Internet use was connected to a decrease in face-toface contact, stress, increased social isolation, sadness, and sleep deprivation. As outcomes, a range of behavioral indicators of mental health and well-being will be evaluated. These will include both general mental health symptoms as well as prior outcomes linked to social media use. Among the latter variables will be Suicidal ideation, social anxiety, loneliness, and a lack of empathy are all symptoms of depression. As expected, among other variables, social desirability was consistently associated with fewer reports of negative symptoms. All negative effects, including suicidal thoughts, were consistently protected by social support. Conflict between parents and children was foreseen. Suicidal thoughts, mental health issues, and loneliness are all too common. It's likely that some forms of social media use serve as a "cry for help" for those who already have mental health issues(Wang and Edwards, 2016). According to those who have been implicated, the government should pay more attention to mental health in the general population. In the midst of a COVID-19 battle, fortunately, the Chinese government has stepped in to help. Mental health UniversePG I www.universepg.com services are available through a variety of channels, including a helpline, an online consultation, and an online course and outpatient consultation, but sadness and anxiety should be given more attention (Wok et al., 2012; Kumari et al., 2021; Pervin \& Hassan, 2020)

\section{CONCLUSION:}

Bangladeshi people face a challenge in the digital world to cope with. Social media and social relations are very important. However, it must be used with restraint and without addiction. Social media has different merits, but it likewise has a few faults that influence individuals contrarily. In organizations, false data can lead the training framework to disappointment. In organizations, the wrong promotion will influence productivity. Online net workings can man-handle the general public by attacking an individual's security. Bangladesh is facing in this digital world both mental issues and social issues related to culture and family. In the real world, family and friends are more important than fancy photos on social media. It is very challenging to balance social media and real social life in the modern world.

\section{ACKNOWLEDGEMENT:}

This study was conducted as the team work of Dhaka University Research Society (DURS). All Authors here are the member of DURS; acknowledge the contribution of Research Manager Muhammad Tanbirul Islam. The authors also want to acknowledge a few folks that have influenced my life. Professor Dr. Md. Akhtaruzzaman, Institute of Nutrition and Food Science, University of Dhaka, Bangladesh. Dr. Kazi Muhammad Rezaul Karim, Institute of Nutrition and Food Science, University of Dhaka, Bangladesh. Dr. Tanjina Rahman, Institute of Nutrition and Food Science, University of Dhaka, Bangladesh

\section{CONFLICTS OF INTEREST:}

The corresponding author and coauthors had no conflict of interest in conducting this research.

\section{REFERENCES:}

1) Amedie, J. (2015). The impact of social media on society.

2) Baskran, S., Mhadi, N. \& Ayob, S. A. (2017). Youth and social media com-portment: A conceptual perspective. International Journal 
of Academic Research in Business and Social

Sciences, 7, 1260-1277.

http://dx.doi.org/10.21111/ejoc.v5i2.5068

3) Bekalu, M. A., Mccloud, R. F. \& Viswnth, K., (2019). Association of social media use with social well-being, positive mental health, and self-rated health: disentangling routine use from emotional connection to use. Health Education \& Behavior, 46, 69S-80S. https://doi.org/10.1177/1090198119863768

4) Butler, B. S. \& Matook. S., (2015). Social media and relationships. The intern. encyclopedia of digital comm. and soc., 1-12.

5) Christensen, S. P., (2018). Social media use and its impact on relationships and emotions, Brigham Young University.

6) FISKE, A. P., (1992). The four elementary forms of sociality: framework for a unified theory of social relations. Psy. review, 99, 689. https://doi.org/10.1037//0033-295X.99.4.689

7) Giddens, A., (1984). The constitution of society: Outline of the theory of structuration, Univ of California Press.

8) Greenhow, C., (2011). Youth, learning, and social media. Journal of Educational Computing Research, 45, 139-146.

http://baywood.com/10.2190/EC.45.2.a

9) Lubis, A. R., Fchrizal, F. \& Lubis, M., (2017). The effect of social media to cultural homecoming tradition of computer students in medan. Procedia Comp. Sci., 124, 423-428. https://doi.org/10.1016/J.PROCS.2017.12.173

10) Lutgendorf, S. K., Degeest, K., \& Sood, A. K., (2009). Depression, social support, and betaadrenergic transcription control in human ovarian cancer. Brain, behavior, and immunity, 23, 176-183.

https://doi.org/10.1016/j.bbi.2008.04.155

11) Orben, A. C. \& Dunbr, R. I. (2017). Social media and relationship development: The eff- ect of valence and intimacy of posts. Computers in Human Behavior, 73, 489-498.

12) Parvez MS, Fatema K, and Mondal DR. (2019). Impact of social networking sites on the interpersonal relationship among teenager: a sociological analysis in the district of Bagerhat. Br. J. Arts Humanit., 1(5), 14-27. https://doi.org/10.34104/bjah.019.14027

13) Phoon, A., (2017). Social Media and its stark influence on society. WRIT: Journal of FirstYear Writing, 1, 8. https://doi.org/10.25035/writ.01.01.08

14) Swyer, R. \& Chen, G.-M., (2012). The impact of social media on intercultural adaptation.

15) Vlenzuela, S., Arriagada, A. \& Scherman, A. (2014). Facebook, Twitter, and youth engagement: A quasi-experimental study of social media use and protest behavior using propensity score matching. Inter. J. of Com., 8, 25.

16) Wang, V. \& Edwards, S., (2016). Strangers are friends I haven't met yet: a positive approach to young people's use of social media. Journal of Youth Studies, 19, 1204-1219.

17) Webster, M., (2012). Social media. Merriam Webster, Incorporated.

18) Wok, S., Idid, S. A., Misman, N. \& Rahim, S., (2012). Social media use for informationsharing activities among youth in Malaysia. Journal. and mass comm, 2, 1029-1047.

19) Kumari, R., Venaik, A., and Sahi, A., (2021). Rep-urposing of the Herbals as ImmuneBoosters in the Prevention and Management of COVID-19: A Review. Journal of Pure and Applied Microbiology, 15(1), pp.1-19. https://doi.org/10.1021/np50107a017

20) Pervin, Z. and Hassan, M., (2020). Synergistic therapeutic actions of antimicrobial peptides to treat multidrug-resistant bacterial infection. Rev. in Med. Microbiol., 32(2), pp.83-89. https://doi.org/10.1021/acs.langmuir.6b00338

Citation: Hasibuzzaman MA, Noboneeta A, Begum M, and Hridi NNC. (2022). Social media and social relationship among youth: a changing pattern and impacts in Bangladesh, Asian J. Soc. Sci. Leg. Stud., 4(1), 0111. https://doi.org/10.34104/ajssls.022.01011 @) () 